\title{
Impact of reservoir operation on sediment deposition
}

\author{
Gregor Petkovsek, Marta Roca ${ }^{1}$
}

${ }^{1}$ HR Wallingford Ltd, Howbery Park, Wallingford, Oxfordshire OX10 8BA, UK

(Email: g.petkovsek@hrwallingford.com)

Paper published in Proceedings of ICE - Water Management, 167 (WM10). pp. 577-584. (2014).

\section{Abstract}

Every year reservoir sedimentation causes an estimated $1 \%$ reduction in the total capacity of reservoirs.

When sediment deposits approach the dam, further issues related to sediment passing through the turbines, blocking of the outlets and dam safety arise. One of possible ways to tackle these problems is management of the sediment in the reservoir itself through a selected operation strategy. A long term reservoir sedimentation model, RESSASS, is used to explore the impact of reservoir operation on sediment deposition. The paper explores the influence of different water level management strategies that result from water supply and hydropower demands. The results show that preserving the live storage may increase the rate of approach of sediment deposits towards the dam. The findings may support reservoir managers when facing these sometimes opposite objectives. To illustrate the analysis, different theoretical strategies are applied to a case study, Tarbela, the largest dam and reservoir on the Indus River in Pakistan.

Keywords: dams, barrages \& reservoirs; management; sustainability

\section{Introduction}

Reservoirs created by dams constitute an important element for providing water to the increasing world population. However, as the river enters the impoundment, the flow velocities decrease and the sediment carrying capacity drops, causing the sediment to deposit. Thus, the storage volume of the reservoir is being lost. It has been estimated that about $1 \%$ of total storage capacity of all reservoirs in the world is lost every year due to sedimentation (Mahmood, 1987; White, 2001). Apart from that, sediment deposited at the upstream end of a reservoirs may also increase flooding probability. Interrupted flow of sediment, particularly in combination with regulated water outflow, has a significant impact on the sediment balance and river morphology of the river reach downstream, as well as its ecological properties. It has been suggested that sediment deposition in the reservoirs is one of the principal problems hindering the sustainable use of surface waters resources developed presently or in the future (Wang et al, 2005).

The majority of existing dams and other impounding structures continuously trap sediment and have no specific provisions for sustained long-term use. The life span of their storage capacity was frequently designed to be less than 100 years (Morris and Fan, 1997), and in practise sometimes reached much shorter duration. A well-known example of a dam structure that had to be reconstructed to cope with the sedimentation problem is the Sanmenxia Dam on the Yellow River in China (Wang et al 2005). The 
reconstruction succeeded in restoring sediment balance in this large reservoir by increasing sedimentreleasing capacity at the outlet. Conveying the turbid waters during the flood season was thus made possible, as well as removal of already deposited sediment by the effect of flushing. Other sediment removal techniques include hydraulic dredging and dry excavation. Sediment management can also be realised outside the reservoir, through reducing sediment inflow either by soil erosion control, upstream sediment trapping or sediment bypass (White, 2001). Any of these solutions will however either consume a proportion of water which will then not be available for reservoir's intended purposes, lower the reservoir levels during the operation, or move the problem to other areas.

From the viewpoint of the dam and reservoir management, there are typically two main concerns regarding sediment. The first is, as mentioned above, the gradual loss of storage volume, which results in reduced capability to provide water for irrigation, hydropower production and other uses, as well as to intercept floods and regulate the flow. The other is associated with the threat that the sediment represents for the dam structure. If the sediment deposits approach the structure too closely, they may block the outlets or even compromise the safety of the dam. The sediment passing through the turbines causes abrasion of mechanical equipment, decreasing its power generating efficiency and ultimately loss of production time during its repair.

Sediment dynamics in the reservoir is greatly affected by the reservoir operation. Most of the sediment load arrives to reservoirs during the high flow events. Keeping the water levels high or filling the reservoir during these events causes most of the incoming sediment to deposit, while keeping the levels low transports more of the inflowing load and may even lead to erosion of the previously deposited sediment. Understanding of the driving forces behind the sediment deposition and their consequences is therefore of high importance in reservoir management.

The consequences of sediment management measures are usually quantified by the use of numerical models capable of simulating long-term reservoir sedimentation. One dimensional models are commonly used for this purpose, as they bring the computational effort to an acceptable level. Their use is justified if the analysed reservoir is long compared to its width, and lateral variations of hydraulic and sediment conditions do not dominate the problem (Simões and Yang, 2006).

In this paper, a numerical study of the influence of reservoir operation strategy to sediment related problems in a reservoir is presented. RESSASS, a long-term reservoir sedimentation model is used for simulation. The data of Tarbela reservoir in Pakistan, completed in 1974, is used in terms of geometry and inflows.

Sedimentation represents a real challenge to the Tarbela reservoir management, as it does in any other reservoir. The principal purpose of the reservoir was to provide water for the extensive irrigation network downstream (TAMS and HR Wallingford, 1998). This is done by regulating the flow of the Indus, storing the volume when the demand is low, until the reservoir is full, and releasing it when the demand is higher than the natural flow, unless the minimum water level is reached. When the water levels are low and the flows high, the sediment deposits may be reworked and transported towards the dam. This may interrupt the power generation, which is the second purpose in this case. The operating levels thus play an important role in assessing the sediment problems.

Various simplified theoretical operation rules are used in the present paper with the aim of making the study and conclusions general. They should therefore be applicable to several structures with no specifically built outlets for flushing of the sediment, as is the case with many reservoirs built in that time (1960s and 1970s). The results presented here provide the impact of operation rules to sedimentation, which may assist the reservoir managers in putting together the whole picture of various and sometimes opposite objectives, targeted by reservoir operation strategy. 


\section{Model}

RESSASS is a 1-D numerical model for simulating sediment dynamics in river and reservoir systems. It predicts long term deposition patterns in reservoirs and loss of storage capacity along with other detailed information such as sediment concentrations, bed composition etc. in cross sections. While most of the sediment transport models used today refer to general open channel conditions, RESSASS was purposely developed for reservoir sedimentation and its computational engine has been designed accordingly. It uses quasy-steady approach, a compromise that makes both reservoir routing (different inflow and outflow of water) as well as large time steps (up to one day) possible.

Flow routing is calculated based on a combination of prescribed time-varying water demand and target levels, limited with outflow rating curve. The iterative scheme for backwater profile tracks the convergence of energy grade line slopes rather than just water levels. Thus the energy grade profiles in the case of low energy slopes, typically occurring in reservoirs, are smooth. In turn, the profiles of shear stresses and transport amounts are computed with appropriate accuracy even at low rates. Additional mixing due to turbulence resulting from flow expansion (Atkinson 1992) is incorporated in the model.

In reservoirs, fine sediment (silt and clay, diameter smaller than $0.06 \mathrm{~mm}$ ) plays an important role. Large concentrations of slit an clay can be transported even when there are no fine fractions present on the bed. In RESSASS, the method of Westrich \& Jurashek (1985) for determining maximum concentration before deposition is adopted in calculations of transport rates of fine sediment. The deposition rate is dependent on the settling velocity according to the method of Krone (1962). Erosion rates are limited by maximum erosion rate according to the formulation by Partheniades (1965). The amount of sediment deposited or eroded at each section is calculated from the difference between predicted transport rates at adjacent cross sections. The sediment mass is converted to volume of deposited material taking into account deposition densities of various size fractions and consolidation effects. Fine fractions of sediment are compacted through time according to the empirical formulae of Lane \& Koelzer (1943) and Miller (1953).

For the sand computations, the concept of a continuous interchange between suspended and bed material, available in the active layer, is implied. The Ackers \& White (1973) sediment transport capacity prediction method revised to consider fine sand (Ackers 1993) was selected for sands in this study. Corrections due to non-equilibrium transport similar to those for fine sediment are applied for sand concentrations, taking into account limiting erosion and deposition rates.

RESSASS has several other options related to reservoir sedimentation: development of scouring channels during flushing, the width of which is obtained from existing empirical relations; modelling of settling velocity based on concentration and shear stress for fine fractions under flocculation conditions; sediment transport in the case of turbidity currents. However these options have not been used in the present study.

RESSASS has been in use since 1990s (HR Wallingford 2001). Throughout this time it has been continuously developed, including a major upgrade recently (HR Wallingford 2013). The latest developments are however only available to in-house users.

Successful calibration and validation against measured data was reported in relation to Tarbela reservoir (e.g. HR Wallingford, 2011; Roca, 2012). The most recent comparison with observed data up to year 2009 was published in Petkovsek and Roca (2013) based on four sets of calibration (from the period between 5 and 20 years after start of operation) and six sets of validation data (23 to 35 years after the start of operation). An example for two selected bed profiles is shown below. 


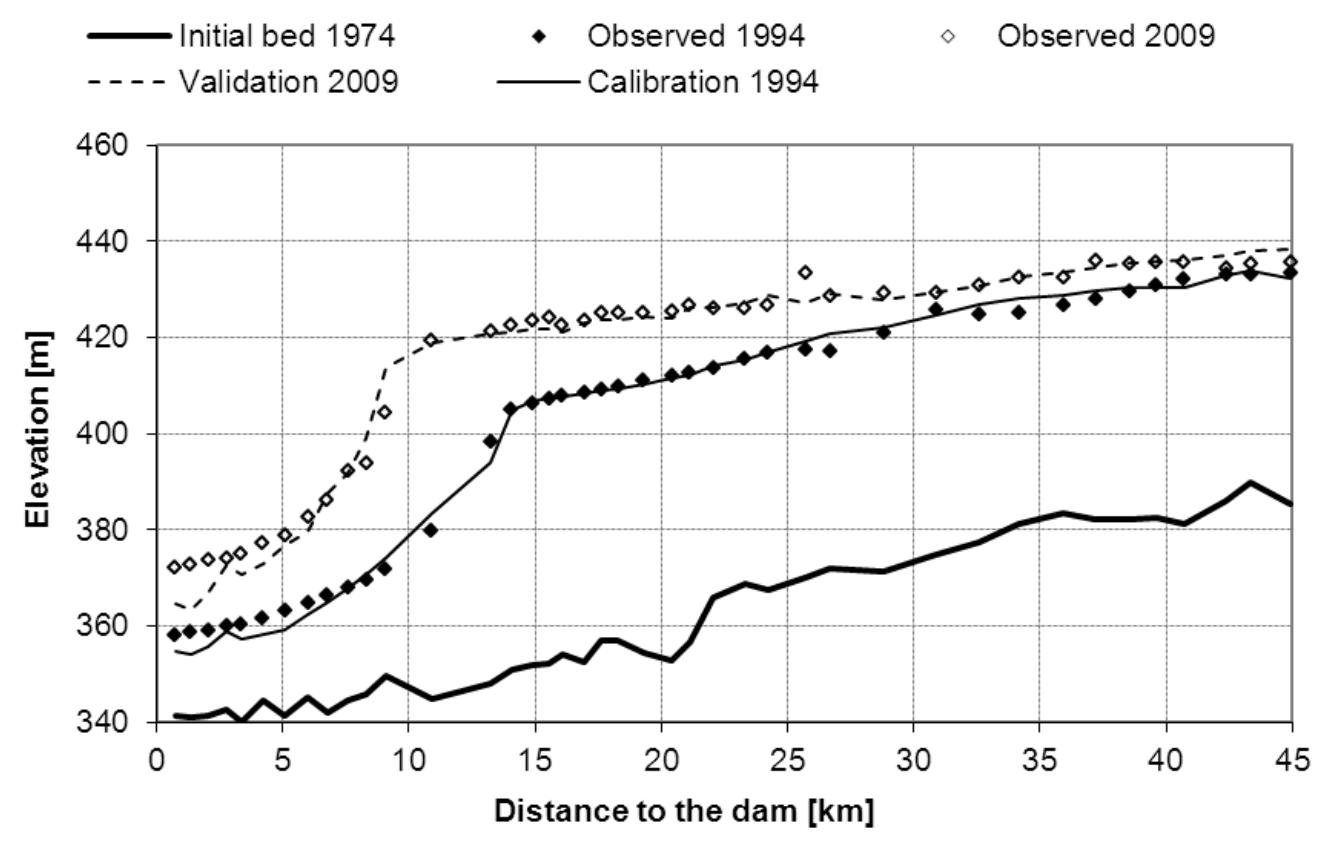

Figure $1 \quad$ Observed, calibrated and validated bed profiles for selected years

\section{Data}

Data from Tarbela reservoir, the largest reservoir in Pakistan and one of the largest in the world, is used in this study. The reservoir can be described as long and narrow. It stretches about $100 \mathrm{~km}$ along the Indus River, while the width of the impounded valley comes to about $5 \mathrm{~km}$ at most. Surveyed range lines were used for modeling (Figure 2). 


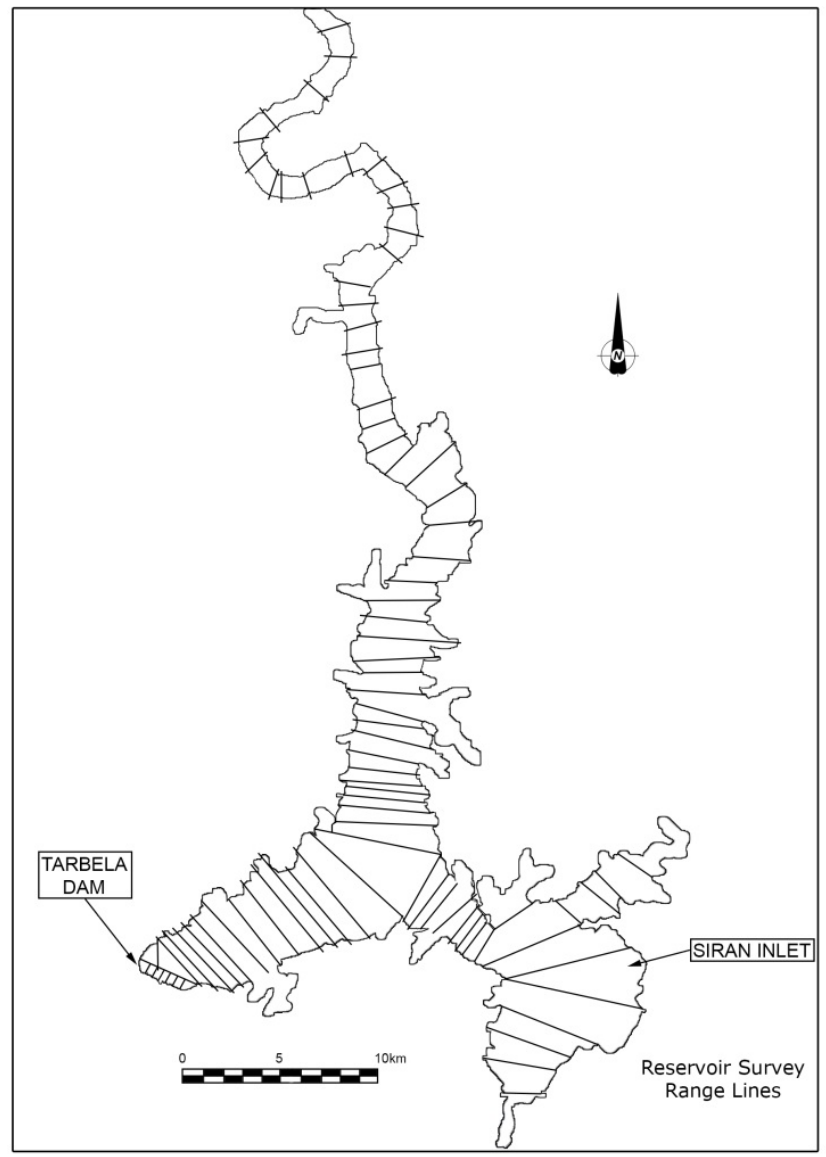

\section{Figure 2 Schematics of Tarbela reservoir with surveyed range lines}

The flow rates of the Indus River depend mainly on the melting of snow and ice in the area of Himalayan and Karakoram mountain ranges. This is supplemented by a monsoon generated rainfall in the area just upstream of the reservoir, producing flash-flood-like peak flows in the summer. The annual maximum discharge typically exceed $10,000 \mathrm{~m} 3 / \mathrm{s}$, and average water inflow into the reservoir is about $2500 \mathrm{~m} 3 / \mathrm{s}$ (TAMS and HR Wallingford 1998). The inflow time series are available for the whole period of reservoir operation. For modeling purpose, 35 years of observed inflows were used and then repeated from the beginning to cover the whole simulated period.

Sediment inflow data was derived based on TAMS and HR Wallingford (1998) report. Average inflowing sediment composition was thus set to $15 \%$ of clay, $50 \%$ of silt and $35 \%$ of sand, including the assumed $10 \%$ of predominantly sandy bed-load. Particles larger than sand were not used for reservoir sedimentation modelling. The sand inflow was assumed to be in equilibrium, i.e. equal to transport capacity of the river cross section upstream from the reservoir. The inflow of fines followed a rating curve obtained from observed concentrations upstream the reservoir. Sediment was split in total of seven fractions, one for clay, four for silt and two for sand.

The operation of the reservoir used to study the impact on reservoir sedimentation was prescribed by simplified reservoir water level curves. The curves have their maximum level (full supply level at $472.44 \mathrm{~m}$ ), minimum level and their durations prescribed. Between them there is a linear decrease, which corresponds to releases of water, and increase, which corresponds to filling of the reservoir (Figure 3). This is a common approach used in studies that predict reservoir sedimentation (TAMS and HR Wallingford, 1998; HR 
Wallingford, 2011; Roca, 2012). It should be noted that the water levels are used by the model as target values. If they cannot be reached due to lack of inflow or structure outflow capacity, the model calculates the water level so that it approaches to the target level as much as possible, given the outflow capacity constraints. The duration of releasing the water from the reservoir is between day 275 (02/10) till day 120 (30/04). The duration of filling of the reservoir is from day 165 (14/06) till day 195 (14/07). Minimum levels and corresponding live storages are listed in the Table 1. The initial bed level at the dam structure is about $340 \mathrm{~m}$ above mean sea level.

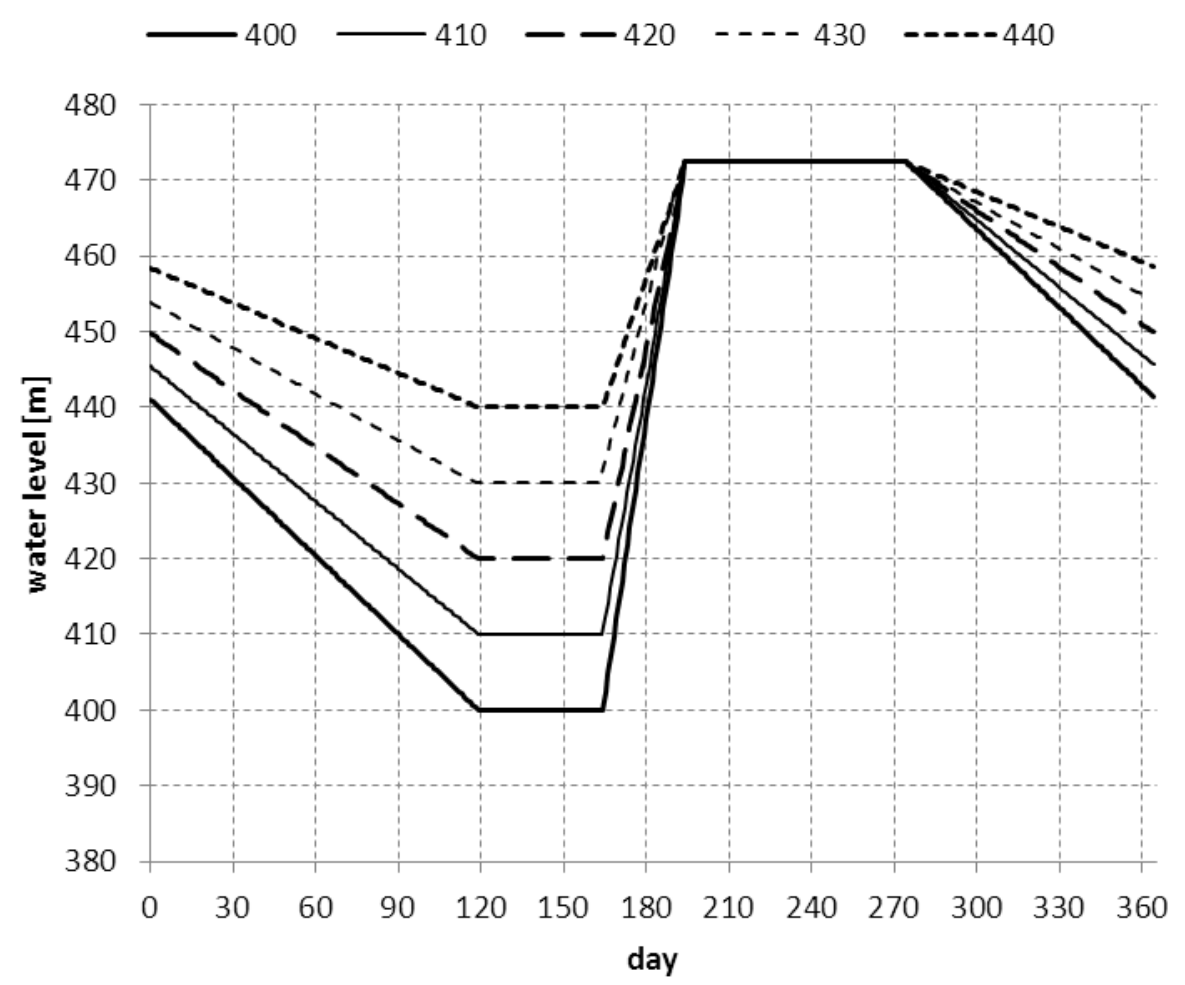

Figure 3 Reservoir operation curves used in the study for one year

Table 1 List of minimum levels for operation curves used in the study and corresponding live storages

\section{Minimum level $[\mathrm{m}] \quad$ Live storage $\left[\mathrm{Bcm}=10^{9} \mathrm{~m}^{3}\right]$}

400

410

420

430

440
11.0

10.0

8.8

7.5

6.0

Finally, two simulations with the change in minimum operation level were run. For the first twenty years, the minimum level was set at $400 \mathrm{~m}$, and later it was changed to 410 in the first and to $420 \mathrm{~m}$ in the second 
simulation. In practical terms, such a change may be prescribed in response to reduce the rate of approach of the sediment deposits towards the dam.

\section{Results}

Simulations have been run for 70 years and the obtained storage capacities, bed profiles of the deposited sediment and amount of sediment outflow were saved. Figure 4 shows the decrease in live storage capacity for the analysed operation curves.

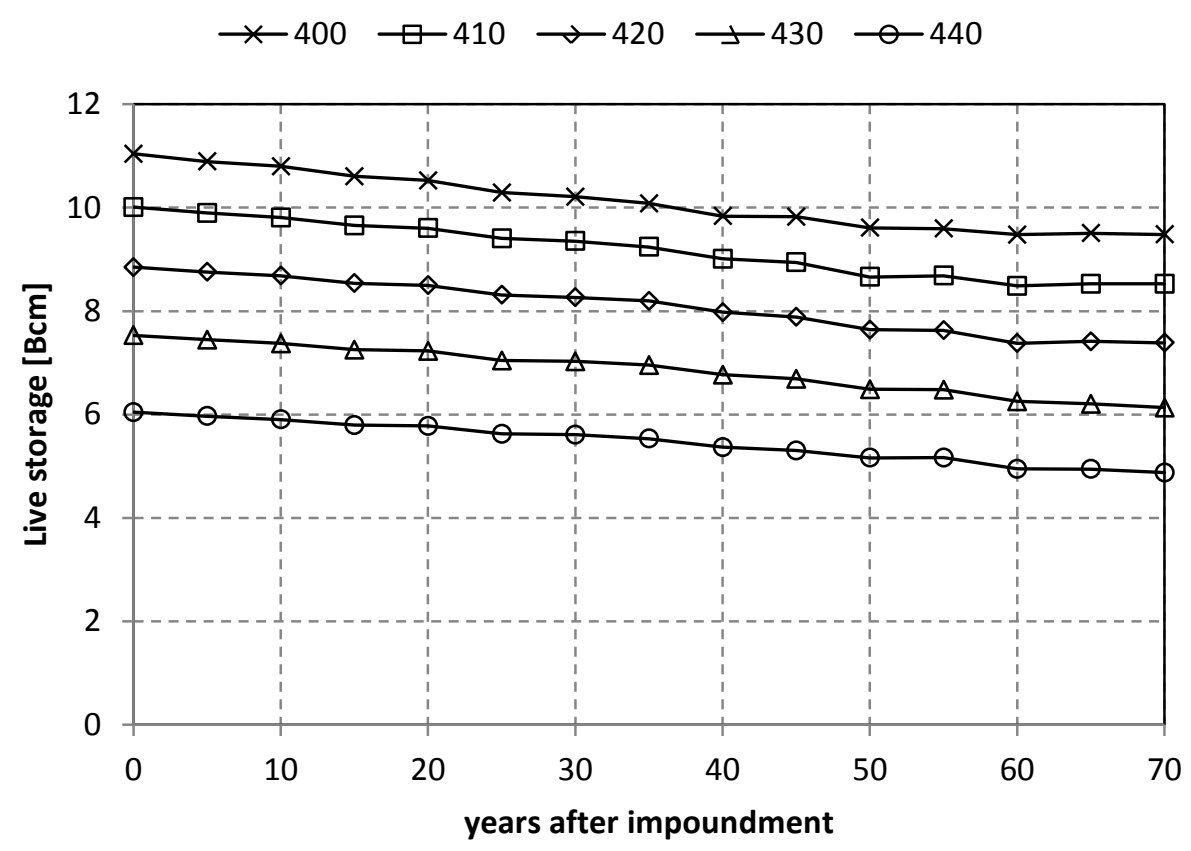

Figure $4 \quad$ Decrease in live storage capacity for the analysed operation curves. The value shown in the legend indicates the minimum operation level.

Results show that there is little difference in the percentage of live storage lost between the different operation rules. After 20 years, the percentage of lost initial live storage is between $4 \%$ and $5 \%$, after 40 years it is between $10 \%$ and $11 \%$ and after 70 years it is between $14 \%$ and $20 \%$, with low minimum operation levels being less affected in terms of relative loss of volume.

From bed profiles, position of the sediment delta pivot point was obtained. The position of the delta was calculated as the distance where the bed profile reaches $1 \mathrm{~m}$ below the minimum operation level. Sample profiles with delta points are shown in Figure 5. Figure 6 shows profiles of the deposits after 20 years for three operation curves. Sediment deposits have advanced further in the case of the low minimum operation level, however the total amount of the deposits is higher in the case of higher minimum operation levels, due to greater thickness of the deposits layer. Table 2 shows the rates at which the delta advances. It can be observed that the rate of approach is faster with lower minimum levels. 

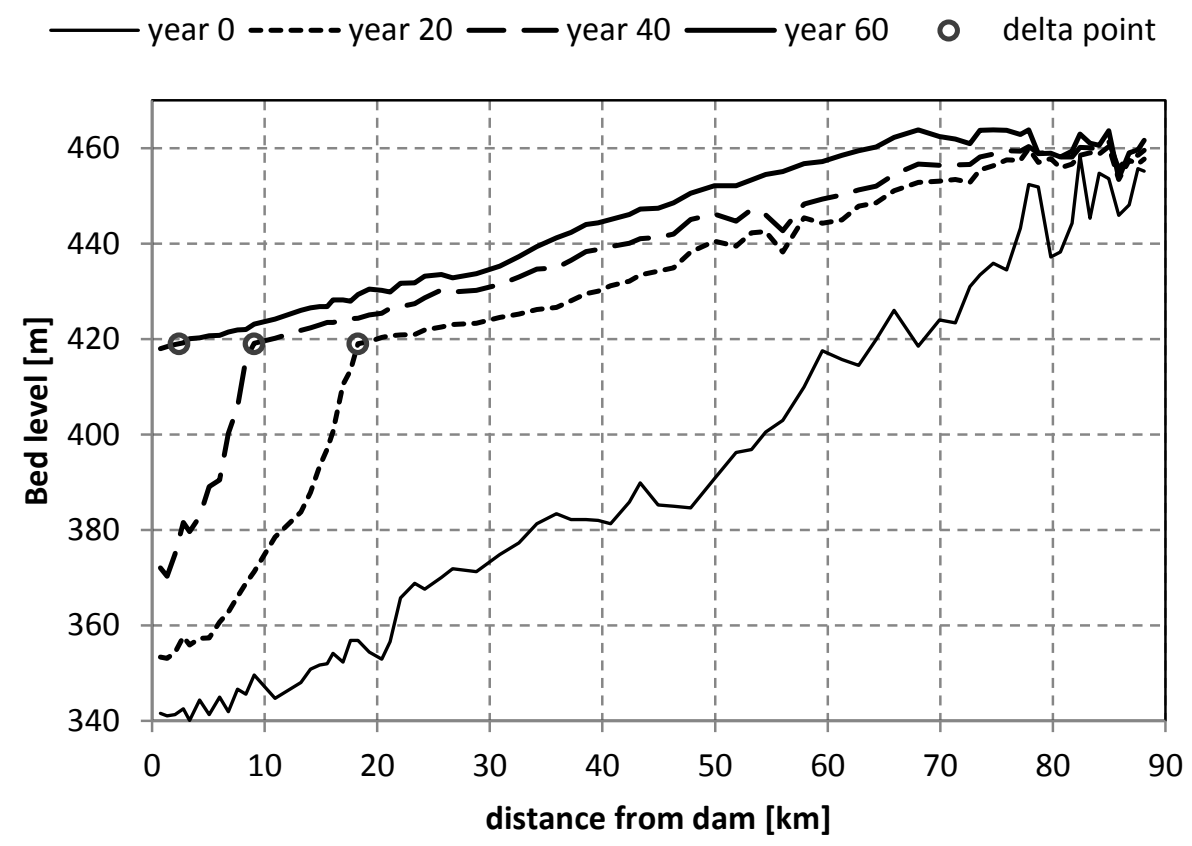

Figure $5 \quad$ Bed profiles of the deposited sediment and calculated delta points for minimum operation level $420 \mathrm{~m}$.

$\longrightarrow$ year 0 - --- min level 400 - min level $420 \longrightarrow$ min level 440

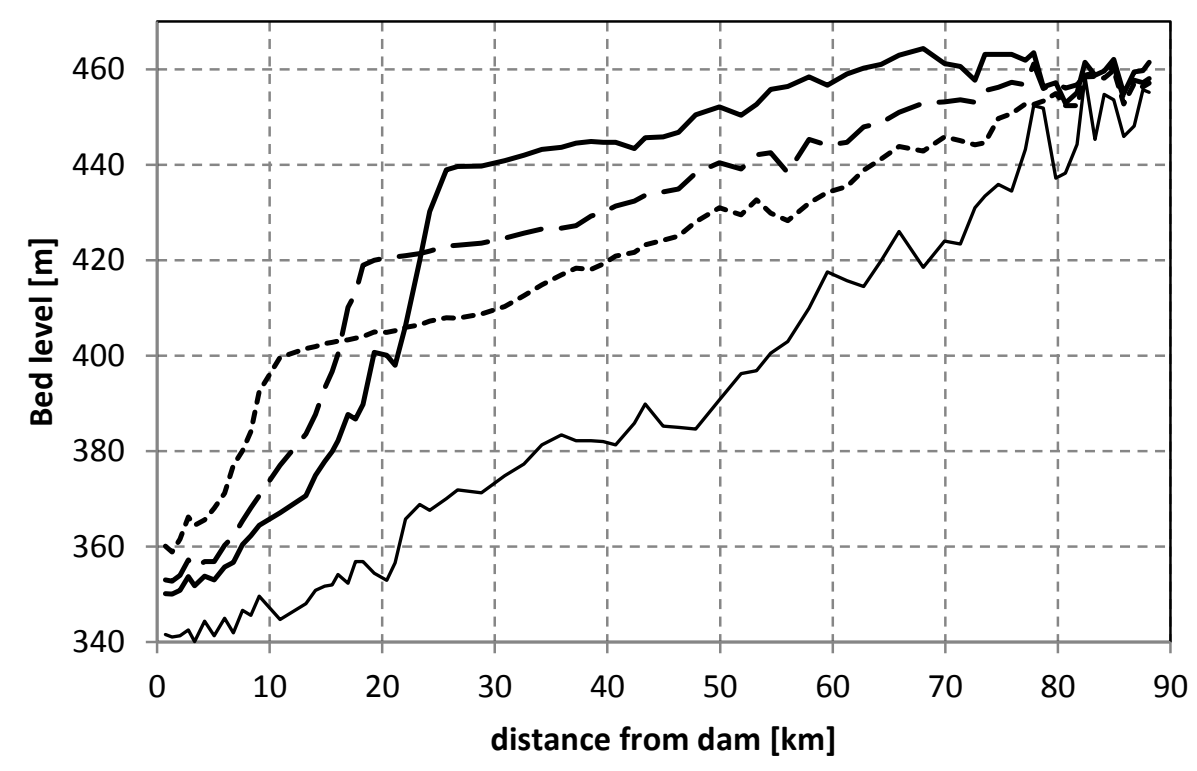

Figure $6 \quad$ Bed profiles of the deposited sediment after 20 years for curves with minimum operation levels of $400 \mathrm{~m}, 420 \mathrm{~m}$ and $440 \mathrm{~m}$. 
Table 2 Approach of sediment deposits (delta pivot point) towards the dam.

\begin{tabular}{|l|l|l|l|l|l|}
\hline Min. operation level [m] & 400 & 410 & 420 & 430 & 440 \\
\hline Delta at $20 \mathrm{~km}$ from dam after [years] & 9 & 13 & 18 & 24 & 30 \\
\hline Delta at $5 \mathrm{~km}$ from dam after [years] & 31 & 41 & 49 & 60 & 75 \\
\hline Rate of approach [km/year] & 0.68 & 0.54 & 0.48 & 0.42 & 0.33 \\
\hline
\end{tabular}

Figure 7 shows the amounts of sediment inflows and outflows from the reservoir.

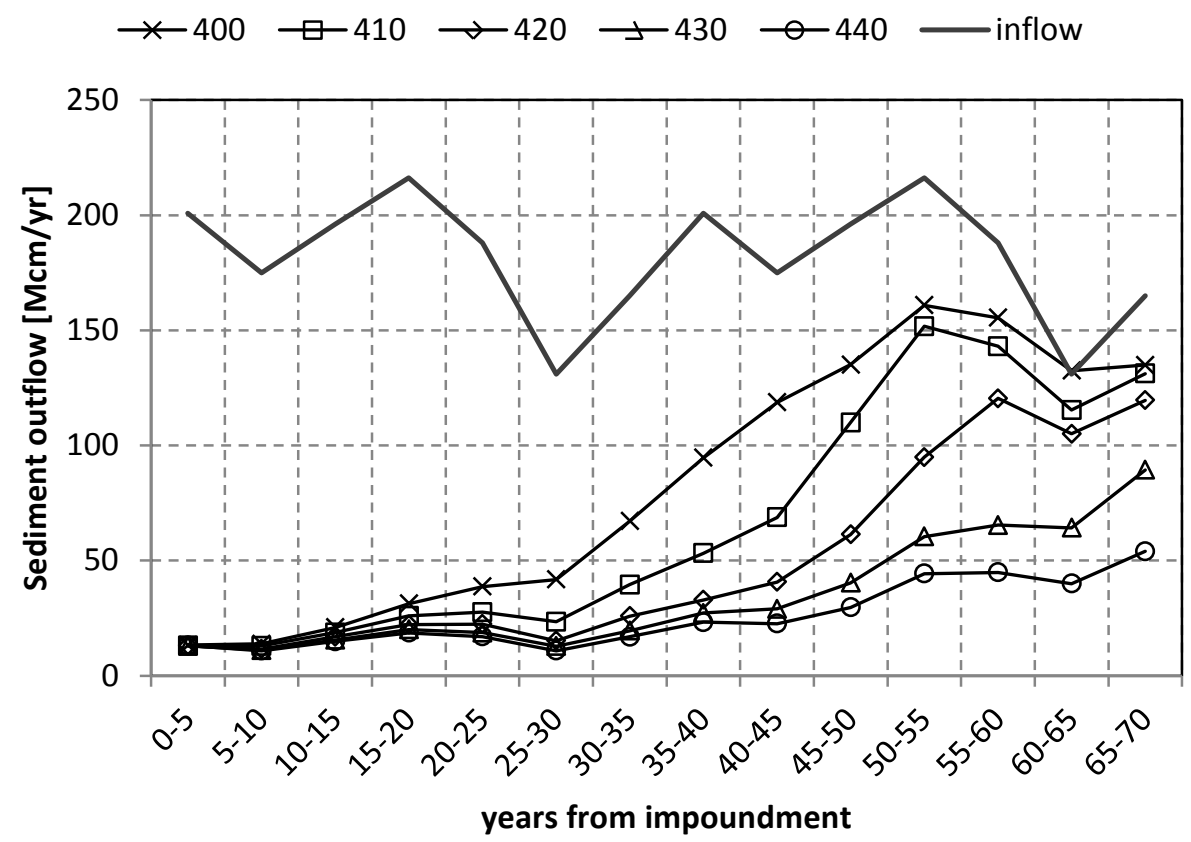

Figure $7 \quad$ Sediment inflows and outflows from the reservoir. The value shown in the legend indicates the minimum operation level.

Sand particles in the outflow significantly contribute to abrasion of outlets' surfaces and turbine blades. Table 3 shows the percentage of sand outflow with respect to sand inflow. For the operation curve with minimum level of $400 \mathrm{~m}$, this is shown further till year 140 in Table 4. The outflows increase with the time and decrease with minimum operation level. Deviations from this rule can be mainly attributed to the variation in sediment inflow. Sand outflows start after about 30-70 years and are initially low, but in the long run they increase to appreciable levels (Table 4).

Table 3 Percentage of sand outflow with respect to sand inflow.

\begin{tabular}{|c|c|c|c|c|c|}
\hline Years from & \multicolumn{5}{|c|}{ Minimum operation level [m] } \\
\hline impoundment & 400 & 410 & 420 & 430 & 440 \\
\hline $0-30$ & 0 & 0 & 0 & 0 & 0 \\
\hline
\end{tabular}




\begin{tabular}{|c|c|c|c|c|c|}
\hline Years from & \multicolumn{5}{|c|}{ Minimum operation level [m] } \\
\hline $30-40$ & 0.1 & 0 & 0 & 0 & 0 \\
\hline $40-50$ & 0.9 & 0.1 & 0 & 0 & 0 \\
\hline $50-60$ & 1.6 & 1.0 & 0.2 & 0 & 0 \\
\hline $60-70$ & 3.2 & 1.8 & 0.8 & 0.1 & 0 \\
\hline
\end{tabular}

Table 4 Percentage of sand outflow with respect to sand inflow for minimum operation level of $400 \mathrm{~m}$, years $70-140$

\begin{tabular}{|l|l|l|l|l|l|l|l|} 
years & $70-80$ & $80-90$ & $90-100$ & $100-110$ & $110-120$ & $120-130$ & $130-140$ \\
\hline RE $[\%]$ & 4 & 7 & 27 & 45 & 65 & 75 & 84 \\
\hline
\end{tabular}

The following section presents the results for the scenarios when the minimum water level is raised after a certain period of years, to keep the sediment deposition taking place away from the dam, once they have approached the dam and sediment outflows have increased. This raise occurs after twenty years of operation from initial $400 \mathrm{~m}$ to $410 \mathrm{~m}$ and $420 \mathrm{~m}$ of minimum water level elevation, respectively. The results of the model show that in the years immediately after the minimum level is raised the sediment outflow drops. The average outflow in the period between years 20 and 25 is $19 \mathrm{Mm} 3$ if the minimum level is raised to $410 \mathrm{~m}$ and $14 \mathrm{Mm} 3$ if raised to $420 \mathrm{~m}$. This is much less than for the case when the minimum level is kept at the $400 \mathrm{~m}$, in which case it is $40 \mathrm{Mm} 3$. It is also less compared to the respective cases when the minimum water level is kept at that raised value from the beginning for the same period between years 20 and 25 , which is $28 \mathrm{Mm} 3$ (for level $410 \mathrm{~m}$ ) and $22 \mathrm{Mm} 3$ (for level $420 \mathrm{~m}$ ). Over the whole period of operation, however, the cumulative outflow of the "raised" scenarios tends to approach that of the constant level scenarios, the reduced outflows after the raise is performed being balanced by the higher outflows in the early period when the minimum water levels are lower.

This can also be seen by comparing the available volumes at the raised levels. Figure 8 presents the increase of available volume between the scenarios where the minimum level is kept at $400 \mathrm{~m}$ in the first 20 years and then raised and the respective constant minimum level scenario. Volume is computed at raised levels in both cases for the whole period. Initially, the volume is gained in the scenarios with initially low minimum levels, but later the difference disappears. 


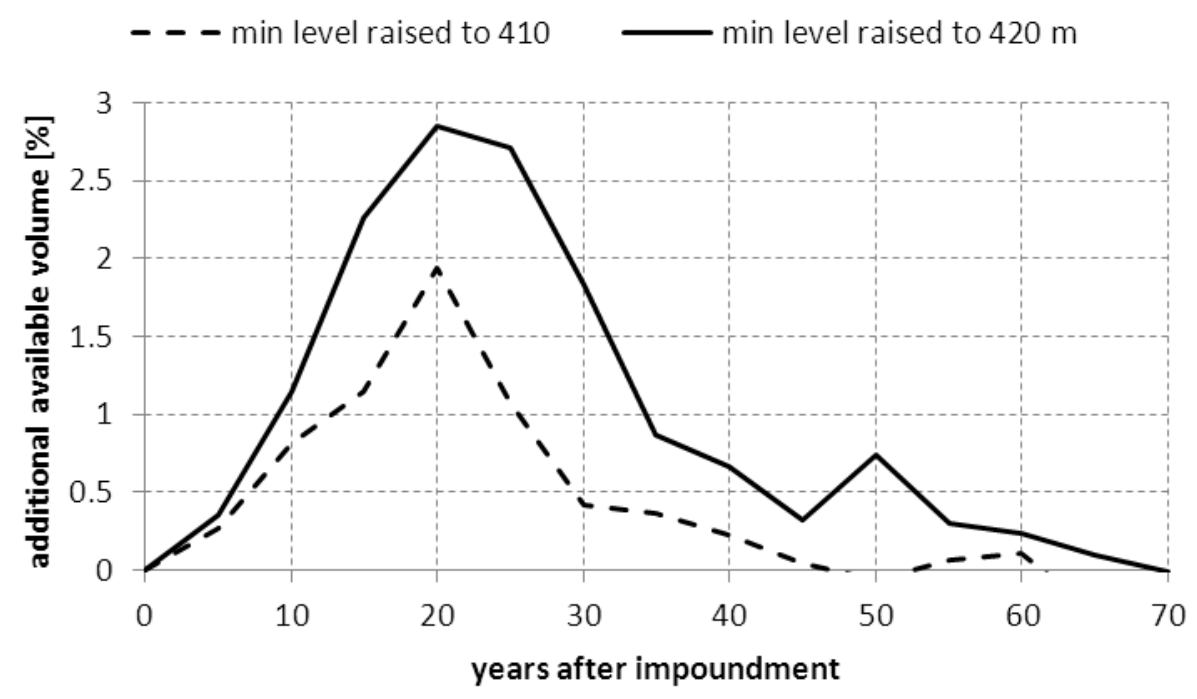

Figure 8

Additional available volume, compared to constant minimum level scenarios, for scenarios where minimum operation level is $400 \mathrm{~m}$ for the first 20 years and then raised to $410 \mathrm{~m}$ and $420 \mathrm{~m}$, respectively

With regards to the advancement of sediment delta pivot point for the scenarios where level is raised after 20 years, the delta reaches $5 \mathrm{~km}$ distance from the dam in the year 36 (level raised to $410 \mathrm{~m}$ ) and 44 (level raised to $420 \mathrm{~m}$ ). Table 5 shows the advancement of the delta pivot point by years for both scenarios.

Table 5 Distance of the sediment delta pivot point from the dam $(\mathrm{km})$ for scenarios where minimum operation level is $400 \mathrm{~m}$ for the first 20 years and then raised to $410 \mathrm{~m}$ and $420 \mathrm{~m}$, respectively.

\begin{tabular}{|l|l|l|l|}
\hline Year & 20 & 30 & 40 \\
\hline Minimum operation level raised to $410 \mathrm{~m}$ & 10.8 & 7.8 & 2.9 \\
\hline Minimum operation level raised to $420 \mathrm{~m}$ & 10.8 & 9.3 & 6.6 \\
\hline
\end{tabular}

\section{Discussion}

Impact of reservoir operation on sediment deposition was studied with a set of prescribed minimum water levels, ranging from $400 \mathrm{~m}$ to $440 \mathrm{~m}$. From the point of view of storage capacity the span of initially available volume is of factor almost 2 (Table 1). Keeping the minimum reservoir level low thus contributes significantly to the volume available for regulation of river flow and releases for irrigation and power production. The loss of available volume is then more or less proportional to the initial volume and for the assumed model setups does not exceed $20 \%$ in 70 years. Most of the sediment is deposited in inactive storage area. This can be seen from Figures 4 and 5. Thus the proportion of loss of total volume is much higher compared to the proportion of loss of available (live) volume only.

Low minimum operation water levels cause more sediment outflow (Figure 7). As the sediment outflow is directly opposite to the amount of sediment deposited in the reservoir, it indicates that the total volume loss is lower. Figure 6 can be consulted to illustrate this. The total volume is important in the case when the operation strategy is later changed by assigning a different minimum operation level, as the available storage 
volume is redefined in this case. Keeping the minimum operation level low in early years, allowing the fine sediment to be released from the reservoir, and raising the minimum level later, is therefore beneficial from this perspective.

In addition to higher outflow, the sediment deposits approach the dam faster in the case of low minimum levels. However both of these effects contribute negatively to the risks associated with the dam function. The former causes wear of the mechanical equipment, in particular power generating turbines. This is mainly associated with sand particles larger than $0.1 \mathrm{~mm}$, but in case of angular quartz particles and high head operation also by smaller particles (Morris and Fan, 1997). The latter may cause blocking or clogging of the outlets or inundate them altogether. The risk is particularly high in the presence of seismic hazard and liquefaction potential of the deposited sediments (TAMS and HR Wallingford, 1998).

According to the model results for the minimum level of $400 \mathrm{~m}$, the sediment outflow increases and in about 60 years almost balances the inflow. However the composition of the inflow and the outflow is not the same. The prescribed percentage for sand inflow is $35 \%$, while in the outflow there is still only very small amount of sand at this point of time. On the other hand, the outflow of fine sediment is higher than its inflow. Therefore the model shows that once the reservoir is full, it reaches the equilibrium in terms of bed level, but the equilibrium in terms of sediment composition is still not achieved. The finer particles in the sediment deposits are being removed and released from the reservoir and in turn replaced with coarser ones that are still trapped. This further delays the passing of the coarser particles through the dam section. Small amounts of sand, however, may be released already when or before the reservoir is fully filled with sediment (sediment delta has reached the dam area).

The scenarios where the minimum operation level is raised show considerable slow-down of the sediment delta advancement. While in the case where the minimum level continues at $400 \mathrm{~m}$, the delta travels between $10.8 \mathrm{~km}$ to $5 \mathrm{~km}$ in 11 years, this time is increased to 16 years if the minimum water level is increased to $410 \mathrm{~m}$ and more than doubled, to 24 years, if the minimum level is increased to $420 \mathrm{~m}$. It should be however noted that this is mainly due to the slow-down in the initial 10 years after the change, when the new sediment delta forms on top of the previous low-lying deposits. The sediment delta still arrives to the dam area earlier than if the minimum water level had been kept at the raised level from the beginning (Table 2), i.e. in 36 instead of 41 years ( $410 \mathrm{~m}$ case) and in 44 instead of 49 years $(420 \mathrm{~m})$. This is balanced out by the benefit of additional storage available, which in year 20 amounts to about $2 \%(410 \mathrm{~m})$ or $3 \%$ (420 m). This additional volume however gradually decreases and disappears in about 20 years (Figure 8).

\section{Conclusions}

While sedimentation is only one element of reservoir management, it is an important one and has to be taken into account. It is also a challenging one, as some objectives may contradict others. For example, the objective of preventing the loss of volume may contradict the objective of passing water with low sediment concentration through the outlets in order to prevent abrasion, in particular if they are equipped with power generation units. Long-term numerical modelling is available and practical for assessing consequences of various operation strategies. For this purpose, numerical model RESSASS was used to predict sediment dynamics within the reservoir. The data from Tarbela, one of the largest reservoirs in the world was used to perform this study.

It is commonly the case that the problem of sedimentation has to be challenged on the level of the reservoir itself, rather than using the measures outside of the reservoir. If the target minimum water levels reached at the end of irrigation season are kept low, the available storage volume will be high, thus allowing good 
regulation of water inflow for irrigation purposes. The discharge of the sediment through the dam section is in this case high at the beginning of the flood season, when levels are low and water discharges high. This may lead to the abrasion of the power generation units. During these periods the outlets with turbines may be closed to avoid the damage, this however leads to the loss of production. Advancement of sediment deposits is also accelerated in this case and may threaten the low-lying outlets by blocking them. On the other hand, if the minimum water level is kept high, these issues are significantly delayed, however the available storage volume is less.

If the minimum level is kept low during the early years of operation and the risk of advancing sediment deposits is observed, the minimum water level may be raised. In this case the advancement of the sediment deposits can be slowed significantly and discharge of sediment through the dam section reduced, in particular in the years following the change. According to the model results for the analysed reservoir, such reduction lasts for a couple of decades if water level is raised 10-20 m.

Reservoir operation levels clearly influence sediment deposition, which in turn influences the capacity of the reservoir to provide flow regulation for irrigation needs and hydropower for energy production through time. At the same time, the operation levels have an impact on the amount of sediment arriving to the dam area. This might compromise the functional aspects of the structure. Reservoir operation rules and their consequences from sedimentation viewpoint have to be taken into account in reservoir management, in order to provide optimal solutions to satisfy economic, environmental and social requirements associated with the reservoir.

\section{References}

Ackers P and White WR (1973) Sediment transport: new approach and analysis. Journal of Hydraulics Division 99(11): 2041-2060.

Ackers P (1993) Sediment transport in open channels: Ackers and White update. Proceedings of the Institution of Civil Engineers - Water, Maritime and Energy 101: 247-249 .

Atkinson E (1992) The design of sluiced settling basins. HR Wallingford, Wallingford, UK, Report OD124.

Hirano M (1971) River bed degradation with armoring. Proceedings of Japanese Society of Civil Engineers 195: 55-65.

HR Wallingford (2001) Measuring and Predicting Reservoir Volume Changes due to Sedimentation. RESSASS Version 1.5. HR Wallingford, Wallingford, UK, User Manual.

HR Wallingford (2011) Tarbela Fourth Extension. Estimation of sediment passing through the turbines. HR Wallingford, Wallingford, UK, Technical Note MCM6764-01.

HR Wallingford (2013) Development of RESSASS-2. HR Wallingford, Wallingford, UK, Report EX6777.

Krone RB (1962) Flume Studies on the Transport of Sediment in Estuarine Shoaling Processes. Hydraulic Engineering laboratory, University of California, Berkeley, California, USA.

Lane EW and Koelzer VA (1943) Density of Sediments Deposited in Reservoirs. Report No. 9, A Study of Methods Used in Measurements and Analysis of Sediment Loads in Streams, Hydraulic Laboratory, University of lowa City, lowa, USA.

Mahmood K (1987) Reservoir Sedimentation. The World Bank, Washington DC, USA, Technical Paper Number 71. 
Miller CR (1953) Determination of the unit weight of sediments for use in sediment volume computations. US Bureau of Reclamation, Denver, USA.

Morris GL and Fan J (1997) Reservoir Sedimentation Handbook. McGraw-Hill, New York, USA.

Partheniades E (1965) Erosion and deposition of cohesive soils. Journal of Hydraulics Division 91: 105-138.

Petkovsek G and Roca M (2013) Importance of selection of processes for modeling long term reservoir sedimentation. In Proceedings of the International Symposium on River Sedimentation 2013. Kyoto, Japan.

Roca M (2012) Tarbela Dam in Pakistan. Case study of reservoir sedimentation. In Proceedings of the International Conference on Fluvial Hydraulics - River Flow 2012. San Jose, Costa Rica.

Simões FJM and Yang CT (2006) Sedimentation Modeling for Rivers and Reservoirs. In Erosion and Sedimentation Manual. U.S. Department of the Interior, Bureau of Reclamation Technical Service Center, Sedimentation and River Hydraulics Group, Denver, Colorado, USA.

TAMS Consultants Inc and HR Wallingford (1998) Tarbela dam sediment management study. WAPDA, Lahore, Pakistan. Final report, Volume 2.

Wang G, Wu B and Wang Zh-Y (2005) Sedimentation problems and management strategies of Sanmenxia Reservoir, Yellow River, China. Water Resources Research 41:1-17.

Westrich B and Juraschek M (1985) Flow transport capacity for suspended sediment. In Proceedings of the 21th Congress of IAHR. Melbourne, Australia.

White R (2001) Evacuating sediments from reservoirs. Thomas Telford, London, UK. 